[Agr.:Biol. Chem., Vol. 28, No. 9, p. 633 638, 1964]

\title{
The Toxicity of Chrysanthemyl-, Allethronyl- and Piperonyl piperonylates and the Higher Homologues
}

\author{
By Tadayoshi Chikamoto \\ Research Laboralory of Dainippon Jotyugiku Co. Ltd., Osaka, Japan
}

Received March 18, 1964

\begin{abstract}
Piperonylic acid and its higher homologues were esterified with ( \pm )-cis-chrysanthemol, $( \pm)$-transchrysanthemol, ( \pm -allethrolone and piperonyl alcohol. The toxicities of the esters against common house fly, Musca domestica vicina Macq., were tested by the topical application method. Three of the esters (entry Nos. 1, 2 and 3) were shown to be slightly toxic. However, further elongation of the ester linkage by methylene groups reduced the biological activity.
\end{abstract}

The chemical structure of the naturally derived pyrethrins were established by Staudinger and Ruzicka $^{1)}$ and LaForge and Barthel ${ }^{2}$, since then many studies concerning the relationship between chemical structure and biological activity have been made and it has become clear that the cyclopropane ring of the acid moiety of the pyrethroid is an important factor for activity. On the other hand, the synergistic action of sesamin for pyrethrins was found ${ }^{3 \text { ) }}$ and many natural and synthetic synergists were reported ${ }^{4}$ ? many of which contain a 3,4-methylenedioxyphenyl group.

Thereupon, the attempts to combine the cyclopropane ring and the 3, 4-methylenedioxypheyl group in the same molecule, for example, piperonyl chrysanthemate which was first prepared by Staudinger and Ruzicka ${ }^{5}$, are reasonable. For this purpose, Barthel and Alexander ${ }^{6}$ ) synthesized chrysanthemates of 6-chloro- and 6bromo-piperonyl alcohols and Takei and Takei ${ }^{7}$

1) H. Staudinger und L. Ruzicka, Helv. Chim. Acta, 7, 177 (1924).

2) F.B. LaForge and W.F. Barthel, J. Org. Chem., 9, 242 (1944);

ibid., 10, $106(1945)$.

3) H.L. Haller, F.B. LaForge and W.N. Sullivan, ibid., 7, 185 (1942); J. Econ. Entomol., 35, 247 (1942).

4) M. Beroza, J. Am. Chem. Soc., 77, 3332 (1955); J. Agr. Food Chem., 4, 53 (1956).

5) H. Staudinger und L. Ruzicka, Hetv. Chim. Acta, 7, 448 (1924)

6) F.W. Barhel and B.H. Alexander, J. Org. Chem., 23, 1012 (1958).

7) S. Takei and S. Takei, This Journal, 24, 459 (I960). reported that allethronyl 2, 2-dimethyl-3-(3', 4'methylenediox yphenyl)-cyclopropane-1-carboxylate were more toxic than $\alpha$ - $( \pm)$-trans-allethrin. All of such compounds were the derivatives of cyclopropane carboxylic acid.

The author attempted to test the insecticidal activities of some new pyrethroid-type compounds which were esters of monocarboxylic acids containing 3,4-methylenedioxyphenyl group and chrysanthemol, allethrolone and piperonyl alcohol.

$( \pm)$-cis- and ( \pm )-trans-Chrysanthemol were prepared by reduction of the corresponding acids. ( \pm )-Allethrolone was obtained from commercial source and piperonyl alcohol was prepared from ethyl piperonylate in the same way as chrysanthemol.

Piperonylic acid was prepared by oxidation of piperonal with potassium permanganate. At first, the preparation of homopiperonylic acid was attempted by Arndt-Eistert reaction of piperonylic acid chloride, of however, the desired homeacid was obtained only in small quantities. It was subsequently synthesized by reduction of piperonylbromacetic acid with acetic acid and zinc dust. 3,4-Methylenedioxyphenyl-propionic acid was prepared from piperonylacrylic acid by catalytic hydrogenation with palladium-charcoal.

The acids were converted into the correspond- 
ing acid chlorides with thionyl chloride and then esterified with alcohols by usual procedures. The liquid esters thus obtained were purified by chromatograph on active alumina column and the crystalline esters were recrystallizde from ethanol.

The toxicities of the esters, together with that of $\alpha-( \pm)$-trans-allethrin as a standard reference, were tested by the topical application method against the common house fly, Musca domestica vicina Macq., and the median knockdown concentrations after thirty minutes. Median lethal concentrations after twenty four hours were determined by Bliss' probit transformation method and given in Table I.

( \pm )-cis-, ( \pm )-trans-Chrysanthemyl piperonylate and $( \pm)$-allethronyl piperonylate are slightly toxic and piperonyl piperonylate is almost inactive. According to the bio-assay with isomeric forms of allethrin ${ }^{8)}$ and 6-chloropiperonyl chrysanthemate ${ }^{9 /}$ by Gersdorff and co-workers, the esters of trans-chrysanthemic acid are more toxic than the corresponding esters of the cis-acid. However contrary to expections, ( \pm )-cis-chrysanthemyl piperonylate is more toxic than $( \pm)$ trans-isomer.

Further elongation of the ester linkage with methylene groups reduced the biological activity as in the case of allethronyl esters of chrysanthemic acid which were reported in a previous paper ${ }^{10)}$.

\section{EXPERIMENTAL}

Melting and boiling points were uncorrected, Microanalyses were carried out by the Microanalitical Division of Mitsui Laboratory of Kyoto University, to whom the author's thanks are due. Infra-red spectra were determined with a Perkin Elmer Model-21 double beam recording spectrophotometer.

( \pm -Allethrolone. Allethrolone from a commercial source was distilled and the center-cut of the pure compound was collected, b.p. $108 \sim 111^{\circ} \mathrm{C} / 0.2 \mathrm{~mm} \mathrm{Hg}, n_{\mathrm{D}}^{24} 1.5140$

\footnotetext{
8) W.A. Gersdorff and N.J. Militin, J. Econ. Entomot., 46, 999 (1952).

9) W.A. Gersdorff, S. K. Freeman and P. G. Piquett, ibid., 51, 76 (19.53).

10) Y. Katsuda, T. Chikamoto and S. Nagasawa, This Journal, 22, 393 (1958).
}

(cf. Freeman reported ${ }^{11)} n_{\mathrm{D}}^{25}$ 1.5164). The infra-red spectrum was identical in every respect with that reported by Freemnn, ${ }^{12)}$

( \pm -cis and $( \pm)$-trans-Chrysanthemol ${ }^{13)}$. Separation of ( \pm )-cis- and ( \pm -trans-chrysanthemic acid: Recrystallization of (士)-cis, trans-chrysanthemic acid mixture from ethyl acetate gave ( \pm )-cis-chrysanthemic acid (m.p. 113 $\sim 114^{\circ} \mathrm{C}$ ).

After removal of the solvent from the filtrate, crude (士)-trans-acid contaminated by cis-acid was obtained. The acid mixture was boiled with $5 \%$ sulfuric acid for three hours and the resulting ( \pm )-chrysanthemolactone from cis-acid was removed by extraction with peteroleum ether and ( \pm -trans- $\delta$-hydroxydihydrochrysanthemic acid from (士)-trans-acid was extracted with ether and the acid was distilled in the presence of $p$-toluenesulfonic acid under a reduced pressure to yield ( \pm -tran 5 -chrysanthemic acid. ${ }^{14}$ b.p. $118 \sim 119^{\circ} \mathrm{C} / 7 \mathrm{~mm} \mathrm{Hg}$.

(土)-cis-Chrysanthemic acid $(28.2 \mathrm{~g})$ in $300 \mathrm{ml}$ of absolute ether was added dropwise into a chilled $\left(-50^{\circ} \mathrm{C}\right)$ solution of lithium aluminum hydride $(6.3 \mathrm{~g})$ in $400 \mathrm{ml}$ of absolute ether under effective stirring. After the addition was complete, the solution was held at $-30^{\circ} \mathrm{C}$ for two hours. Then it was allowed to stand at room temperature overnight. Excess hydride was decomposed by addition of water at $-20 \sim-30^{\circ} \mathrm{C}$, and then $250 \mathrm{ml}$ of $10 \%$ sulfuric acid was added to the mixture and it was allowed to reach $15^{\circ} \mathrm{C}$. The ethereal solution was separated and washed with dilute aqueous solution of sodium hydroxide, dilute hydrochloric acid and water. After removal of ether, distillation of the residual oil gave (士)-cis-chrysanthemol $\left(23.5 \mathrm{~g}\right.$ ), b.p. $63 \sim 64^{\circ} \mathrm{C} / 2 \mathrm{~mm} \mathrm{Hg}$, $n_{\mathrm{D}}^{20} 1.4760$.

By the same procedure described above, ( \pm -)iranschrysanthemic acid $(13.5 \mathrm{~g})$ and lithium aluminum hydride $(3 \mathrm{~g})$ gave $( \pm)$-trans-chrysanthemol $(11.5 \mathrm{~g})$, b.p. $70 \sim$ $72^{\circ} \mathrm{C} / 3 \mathrm{~mm} \mathrm{Hg}, n_{\mathrm{D}}^{20} 1.4700$.

Piperonyl alcohol. Ethyl piperonylate ${ }^{15\rangle}(28 \mathrm{~g})$ b.p. $119 \sim 120^{\circ} \mathrm{C} / 3.5 \mathrm{~mm} \mathrm{Hg}$, was reduced with lithium aluminum hydride $(5 \mathrm{~g})$ by the same method as chrysanthemic acid. The resulting product $(21 \mathrm{~g})$ was recrystallized from ether-peteroleum ether $(3: 2)$ and melted at $53 \sim 53.5^{\circ} \mathrm{C}$ Anal. Found: C, $63.28 ; \mathrm{H}, 5.47$. Calcd. for $\mathrm{C}_{8} \mathrm{H}_{8} \mathrm{O}_{3}: \mathrm{C}$, $63.15 ; 5.30 \%$.

Piperonyl acid. ${ }^{16)}$ Piperonal $(60 \mathrm{~g})$ was suspended in

11) S.K. Freeman, Anal. Chem., 25, 646 (1953)

12) S.K. Freeman, ibid., 27, 1270 (1955).

13) $Y$. Inouye and $M$. Ohno, This Journal, 20, 25 (1956).

14) M. Matsui and co-works, ibid., 19, 159 (1955).

15) J. Jobst und O. Hesse, Ann., 119,69 (1879).

16) R. Fittig und W.H. Mielch, ibid, 152, 40 (1869). 
$1500 \mathrm{ml}$ of water and treated with potassium permanganate $(90 \mathrm{~g})$ in $1800 \mathrm{ml}$ of water at $70 \sim 80^{\circ} \mathrm{C}$. The crude acid $(60 \mathrm{~g})$ was recrystallizad from ethanol and melted at $225 \sim 226^{\circ} \mathrm{C}$ Anal. Found: C, 58.09; H, 3.93. Calcd. for $\mathrm{C}_{8} \mathrm{H}_{6} \mathrm{O}_{4}: \mathrm{C}, 57.83 ; \mathrm{H}, 3.64 \%$.

Homopiperonylic acid. Ethyl 3,4-methylenedioxymandelate $\left.{ }^{17}\right)$ : Piperonal $(100 \mathrm{~g})$ was melted and a concentrated solution of sodium hydrogen sulphite $(75 \mathrm{~g})$ in warm water was added. The addition compound was collected and washed with cold water. The product was made into a thick paste with a small amount of water and cold aqueous saturated solution of sodium cyanide $(50 \mathrm{~g})$ was added to the paste. The resulting oil of piperonalcyanohydrin was extracted with ether. After drying, $10 \mathrm{ml}$ of ethanol was added to the solution and the mixture was saturated with hydrogen chloride at $0 \sim$ $5^{\circ} \mathrm{C}$. On standing for thirty minutes, the solution solidified into a mass of crystals and the crystals warmed with water. The ester $(83 \mathrm{~g})$ was obtained as an oil which solidified on cooling. It was crystallized from xylene and melted at $66 \sim 67^{\circ} \mathrm{C}$.

The ester $(50 \mathrm{~g})$ was refluxed with $500 \mathrm{ml}$ of $10 \%$ ethanolic potassium hydroxide for three hours. The resulting solution was almost neutralized with dilute hydrochloric acid, filtered and the solvent was removed under a reduced pressure and the residue was dissolved in a little amount of water. On acidification, 3,4methylenedioxymandelic acid separated and was recrystallized from aqueous ethanolic solution $(1: 1), 41 \mathrm{~g}, \mathrm{~m} . \mathrm{p}$. $157 \sim 158^{\circ} \mathrm{C}$.

The acid $(36 \mathrm{~g})$ was dissolved in $400 \mathrm{ml}$ of acetic acid at $50 \sim 60^{\circ} \mathrm{C}$ and dry hydrogen bromide $(36 \mathrm{~g})$ was passed into the solution. ${ }^{19)}$ After two hours, the resulting piperonylbromoacetic acid was reduced by addition of zinc dust $(40 \mathrm{~g})$. The mixture was heated on a boiling water bath for two hours, and then $200 \mathrm{ml}$ of concentrated hydrochloric acid added. When the solution was diluted with water, crude homopiperonylic acid (28 g) was obtained. It was recrystallized from aqueous ethanolic solution (1:1) and melted at $128 \sim 129^{\circ} \mathrm{C}$, Anal. Found: C, 60.17; H, 4.53. Calcd. for $\mathrm{C}_{9} \mathrm{H}_{7} \mathrm{O}_{4}: \mathrm{C}, 60.00 ; \mathrm{H}, 4.48 \%$.

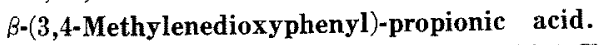

Piperonylacrylic acid $\left(9.6 \mathrm{~g}\right.$, m.p. $236 \sim 236.5^{\circ} \mathrm{C}$ ) was suspended in $60 \mathrm{ml}$ of ethanol and hydrogenated with Pdcharcoal catalyst, which contained $0.024 \mathrm{~g}$ of $\mathrm{Pd}$, in a shaking bydrogenation apparatus and absorbed $1121.5 \mathrm{ml}$ of hydrogen (at $32^{\circ} \mathrm{C}$ ), equivalent to $1 \mathrm{~mol}$., giving $\beta$ - $(3,4-$ methylenedioxyphenyl)-propionic acid, m.p. $85.5 \sim 86.5^{\circ} \mathrm{C}$ from aqueous ethanolic solution (1:1), Anal. Found: C,

17) G. Barger and A.J. Ewins, J. Chem. Soc., 95, 554 (1909).

18) T.S. Stevens, f. Chem. Soc, $1927,181$.
$61.91 ; \mathrm{H}, 5.32$. Calcd for $\mathrm{C}_{10} \mathrm{H}_{10} \mathrm{O}_{4}: \mathrm{C}, 61.85 ; \mathrm{H}, 5.19 \%$.

Esterification. General procedure: Piperonylic acid was refluxed with an excess of thionyl chloride for one hour. After removal of excess of thionyl chloride, the residue was distilled in vacuo, b.p. $115 \sim 116^{\circ} \mathrm{C} / 4 \mathrm{~mm} \mathrm{Hg}$. The acid chloride was dissolved in dry benezene. A calculated amount of alcohol and a slightly excess of dry pyridine in a small amount of dry benzene was added to the acid chloride solution and the mixture was allowed to stand at room temperature for two days. The resulting pyridine hydrochloride was removed by filtration and the solution was washed with water, dilute sodium bicarbonate solution, dilute hydochloric acid and water, and dried. The solvent was removed under a reduced pressure in nitrogen atmosphere.

Homopiperonylic acid was refluxed with a slight excess of thionyl chloride in a small amount of dry benezene for one hour. After removal of the solvent and excess thionyl chloride under reduced pressure, the residual acid chloride was treated in the same way as described above.

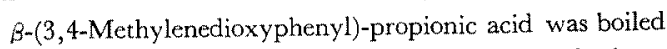
with calculated amount of phosphorous trichloride in a small amount of dry ether for one hour. After separation of resulting phosphoric acid by decantation, the acid chloride was treated according to the same procedure.

The solid esters were recrystallized from ethanol and the liquid esters were dissolved in ether-peteroleum ether mixture $(1: 1)$ and chromatographed on active alumina columns and the solvent of the elute was removed in vacuo in nitrogen atmosphere. The infra-red spectra. fully substantiated the expected structures.

(士)-cis-Chrysanthemyl piperonylate. The yield was $82.8 \%$ of the theoretical, m.p. $63 \sim 63.5^{\circ} \mathrm{C}$ Anal. Found: $\mathrm{C}$, 71.34; $\mathrm{H}$, 7.36. Calcd. for $\mathrm{C}_{18} \mathrm{H}_{22} \mathrm{O}_{4}: \mathrm{C}, 71.50$; $\mathrm{H}, 7.33 \%$.

( \pm -trans-Chrysanthemyl piperonylate. The yield was $82.8 \%$ of the theoretical, m.p. $51.5 \sim 52^{\circ} \mathrm{C}$ Anal. Found: $\mathrm{C}, 71.33 ; \mathrm{H}, 7.34$.Calcd. for $\mathrm{C}_{18} \mathrm{H}_{22} \mathrm{O}_{4}: \mathrm{C}, 71.50$; $\mathrm{H}, 7.33 \%$ ).

(士)-Allethronyl piperonylate. The yield was $82.8 \%$ of the theoretical, m.p. $64 \sim 65^{\circ} \mathrm{C}$ Anal. Found: C, 68.11 ; $\mathrm{H}, 5.49$. Calcd. for $\mathrm{C}_{17} \mathrm{H}_{16} \mathrm{O}_{5}: \mathrm{C}, 67.99 ; \mathrm{H}, 5.37 \%$.

Piperonyl piperonylate. The yield was $72.4 \%$ of the theoretical, m.p. $91 \sim 92^{\circ} \mathrm{C}$ Anal. Found: C, $63.90 ; \mathrm{H}$, 4.10. Calcd. for $\mathrm{C}_{16} \mathrm{H}_{12} \mathrm{O}_{6}: \mathrm{C}, 64.00 ; \mathrm{H}, 4.03 \%$.

(士)-cis-Chrysanthemyl homopiperonylate. The yield was $48.4 \%$ of the theoretical $n_{\mathrm{D}}^{20} 1.522$.

( \pm -trans-Chrysanthemyl homopiperonylate. The yield was $44.3 \%$ of the theoretical, $n_{\mathrm{D}}^{20} 1.5200$.

(士)-Allethronyl homopiperonylate. The yield was 
$73.2 \%$ of the theoretical, m.p. $95.5 \sim 96^{\circ} \mathrm{C}$ Anal. Found:

C, 68.74; $\mathrm{H}, 5.67$. Calcd. for $\mathrm{C}_{18} \mathrm{H}_{18} \mathrm{O}_{5}: \mathrm{C}, 68.78$; $\mathrm{H}, 5.77 \%$.

Piperonyl homopiperonylate. The yield was $76.4 \%$ of the theoretical, m.p. $60 \sim 61^{\circ} \mathrm{C}$ Anal. Found: C, 64.72 ; $\mathrm{H}, 4.49$. Calcd. for $\mathrm{C}_{17} \mathrm{H}_{14} \mathrm{O}_{6}: \mathrm{C}, 64.96 ; \mathrm{H}, 4.49 \%$.

$( \pm)$-cis-Chrysanthemyl $\beta$-(3,4-methylenedioxy-

phenyl)-propionate. The yield was $43.3 \%$ of the theoretical, $n_{\mathrm{D}}^{20} 1.5168$.

(士)-trans-Chrysanthemyl $\beta-(3,4$-methylenedioxyphenyl)-propionate. The yield was $46.4 \%$ of the theom retical, $n_{\mathrm{D}}^{20} 1.5207$.

(士)-Allethronyl $\beta$-(3,4-methylenedioxyphenyl)-

propionate. The yield was $43.9 \%$ of the theoretical, $n_{\mathrm{D}}^{20} 1.5410$.

Piperonyl $\beta$-(3,4-methylenedioxyphenyl)-propionate. The yield was $43.6 \%$ of the theoretical $n_{\mathrm{D}}^{20} 1.5723$.

Biological assay

Twelve compounds as listed in Table $I$ and $\alpha-( \pm)$ trans-allethrin were dissolved in acetone at three to four concentrations.
The tests were carried out according to the topical application method on adults of common house fly, Musca domestida vicine Macq., reared by the standard procedure using a culture medium prepared with okara. ${ }^{19)}$ While adult flies of undetermined sex-ratio, were immobilized by a low temperature, $0.0006 \mathrm{ml}$ of an acetone solution of a toxicant was applied topically with a micrometeroperated syrings to the scutum portion of each fly. After treatment, the flies were transfered to petri-dishes, provided with wheat paste as a diet, and kept at room temperature until knockdown counts thirty minutes later and mortality counts twenty four hours later were made.

The knockdown and mortality data are summarized in Table II. Median knockdown and lethal concentrations were assessed from the equations of concentration-knockdown and concentration-mortality regression lines, and relative toxicities were calculated as inverse ratios of $\mathrm{KC}$ 50 's and LC- 50 's, as given in Table I.

Acknowledgements The author is indebted to Emeritus Prof. S. Takei, Prof. M. Ohno and

Table I. Evaluation of Relative Effectiveness on Toxicity of the Esters of Piperonylic ACID and its Higher Homologues

AS COMPARED WITH $\alpha$-(士)-trans-ALLETHRIN<smiles>[R]OC(=O)CCc1ccc2c(c1)OCC2</smiles>

\begin{tabular}{|c|c|c|}
\hline Series & Entry & Material \\
\hline 1 & $\begin{array}{l}1 \\
2\end{array}$ & $\begin{array}{l}\alpha-( \pm) \text {-trans-allethrin } \\
a-a^{\prime} \\
a-b^{\prime}\end{array}$ \\
\hline 2 & 3 & $\begin{array}{l}\alpha-( \pm) \text {-trans-allethrin } \\
\mathrm{a}-\mathrm{c}^{\prime}\end{array}$ \\
\hline 3 & $\begin{array}{l}4 \\
5 \\
6 \\
8\end{array}$ & $\begin{array}{l}\alpha-( \pm) \text {-trans-allethrin } \\
a-d^{\prime} \\
b-a^{\prime} \\
b-b^{\prime} \\
b-d^{\prime}\end{array}$ \\
\hline 4 & $\begin{array}{r}7 \\
9 \\
10 \\
11 \\
12\end{array}$ & $\begin{array}{l}\alpha-( \pm) \text {-trans-allethrin } \\
\mathrm{b}-\mathrm{c}^{\prime} \\
\mathrm{c}-\mathrm{a}^{\prime} \\
\mathrm{c}-\mathrm{b}^{\prime} \\
\mathrm{c}-\mathrm{c}^{\prime} \\
\mathrm{c}-\mathrm{d}^{\prime}\end{array}$ \\
\hline
\end{tabular}

$$
\begin{array}{ll}
\text { Acid } & \text { Alcohol } \\
\text { a: } n=0 & \mathrm{a}^{\prime}: \mathrm{R}=( \pm) \text {-cis-Chrysanthemyl } \\
\mathrm{b}: \mathrm{n}=1 & \mathrm{~b}^{\prime}: \mathrm{R}=( \pm) \text {-trans-Chrysanthemyl } \\
\mathrm{c}: \mathrm{n}=2 & \mathrm{c}^{\prime}: \mathrm{R}=( \pm) \text {-Allethronyl } \\
& \mathrm{d}^{\prime}: \mathrm{R}=\text { Piperonyl }
\end{array}
$$

Median knockown concentration

\begin{tabular}{cl}
\hline KC-50 & $\begin{array}{c}\text { knockdown } \\
\text { effectiveness }\end{array}$ \\
$0.10 \%$ & 1.00 \\
1.97 & 0.05 \\
5.23 & 0.02 \\
0.14 & 1.00 \\
5.12 & 0.03 \\
0.13 & 1.00 \\
$763.0^{*}$ & 0.00007 \\
- & - \\
- & - \\
0.02 & - \\
32.05 & 0.001 \\
- & - \\
- & -
\end{tabular}

Median lethal concentration

LC-50 $\begin{gathered}\text { Lethal } \\ \text { effectiveness }\end{gathered}$

$\begin{array}{cl}0.10 \% & 1.00 \\ 4.27 & 0.02 \\ 5.60 & 0.02 \\ 0.07 & 1.00 \\ 3.77 & 0.02 \\ 0.14 & 1.00 \\ 469.5^{*} & 0.0003 \\ 100,570.0^{*} & 0.000001 \\ 671.05^{*} & 0.0002 \\ 413,550.0^{*} & 0.0000003 \\ 0.03 & 1.00 \\ 37.70 & 0.001 \\ - & - \\ - & - \\ - & -\end{array}$

* The value in parenthese is not realized. 
Table II. Concentration-Knockdown and Concentration-Mortality of

Adults of the Common House Fly, Musca domestica vicina Macq., for Esters of Piperonylic Acid and Higher Homologues Applied Topically as Acetone Solution

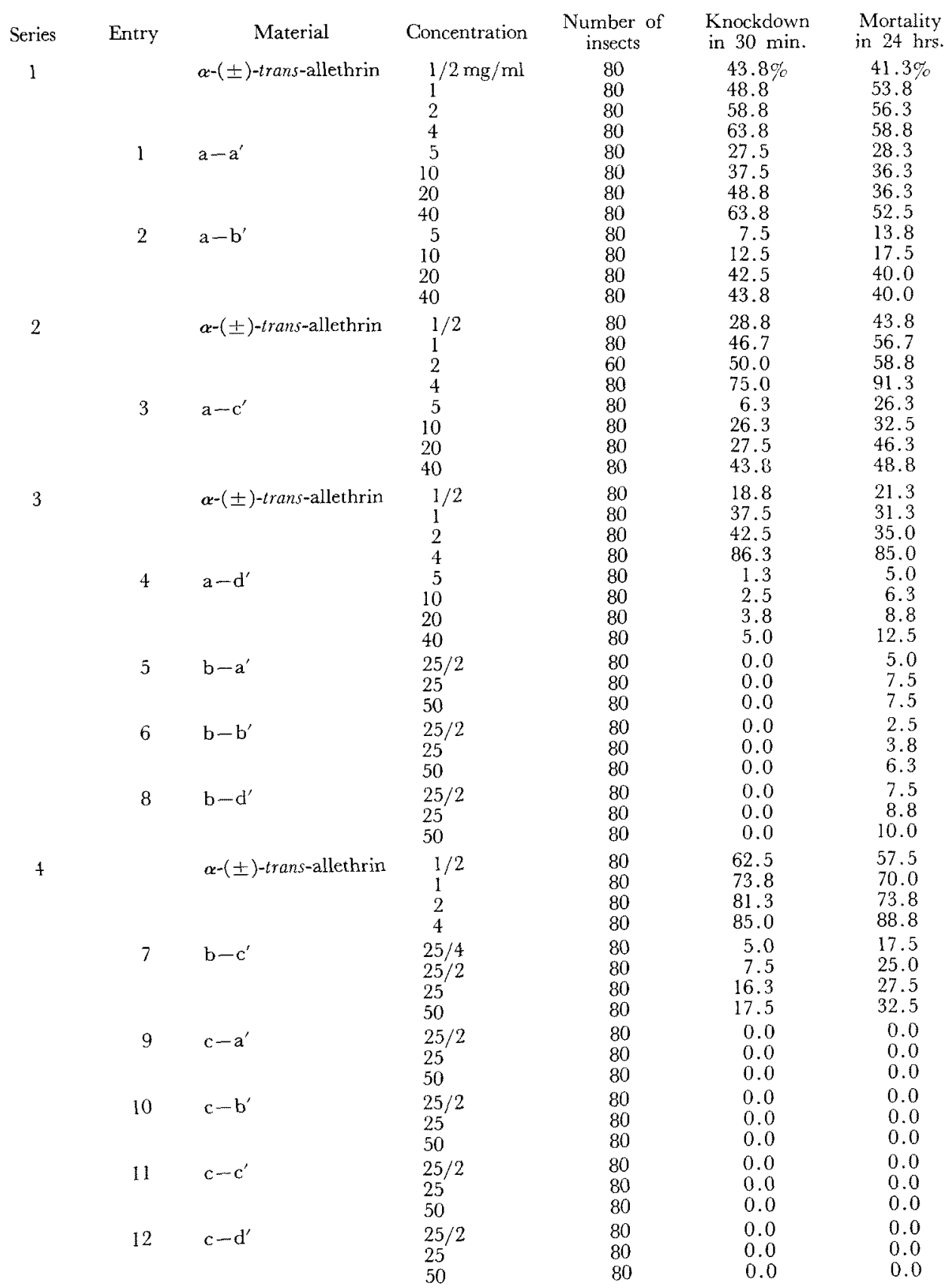


Dr. Y. Inouye of Kyoto University for their useful advice and also Mr. K. Uyeyama, Pre- sident of this Company, for his encouragement in the course of this work. 